${ }^{1}$ Department of Pediatric Dentistry and Orthodontics. Faculty of Dentistry. Federal University of Minas Gerais, Brazil.

E-mail: leniananeves@gmail.com

${ }^{2}$ Department of Orthodontics. Uninassau, Recife, Pernambuco, Brazil. E-mail: luizfiliphecanuto@yahoo. com.br

${ }^{3}$ Department of Orthodontics, Ingá Faculty, Maringá-PR, Brazil. E-mail:rohercan0207@gmail.com

4 Department of Orthodontics. Bauru Dental School, University of São Paulo, Brazil.

E-mail: jansong@travelnet.com.br

${ }^{5}$ Department of Pediatric Dentistry and Orthodontics. Faculty of Dentistry. Federal University of Minas Gerais, Brazil.

E-mail: afdorto@googlemail.com

${ }^{6}$ Department of Orthodontics. Bauru Dental School, University of São Paulo, Brazil.

E-mail: jfchenri@fob.usp.br

Corresponding author:

Dr. Leniana Santos Neves

Department of Pediatric Dentistry and Orthodontics

Faculty of Dentistry

Federal University of Minas Gerais

Av. Presidente Antônio Carlos, 6627 ampulha-31270-901

Belo Horizonte - MG

Brazil

Phone: 5531 3409-2426

E-mail: leniananeves@gmail.com

Received: May 06, 2018

Accepted: November 19, 2018

\section{Influence of fixed appliances on two-phase orthopedic-orthodontic treatment}

\author{
Leniana Santos Neves ${ }^{1}$, Luiz Filiphe Gonçalves \\ Canuto $^{2}$, Rodrigo Hermont Cançado ${ }^{3}$, Guilherme \\ Janson ${ }^{4}$, Alexandre Fortes Drummond ${ }^{5}$, José \\ Fernando Castanha Henriques ${ }^{6}$
}

Aim: The purpose of this retrospective study was to investigate the effects of phase 2 with fixed appliances, after phase 1 Bionator treatment of Class $\|$ division 1 malocclusion, as compared to a matching control group. Methods: The experimental group consisted of 20 patients who were evaluated after orthodontic treatment with fixed appliances subsequently to functional therapy with the Bionator in phase 1. A control group consisting of 20 Class II, division 1 individuals. Results: During phase 1 there was significant forward growth restriction in the maxillary complex, improvement of the maxillomandibular relationship and decrease in facial convexity. There was also significant reduction of the maxillary incisor proclination and protrusion, protrusion of the mandibular incisors, and vertical development of the mandibular molars. The overjet was significantly reduced and the molar relationship was significantly improved. Treatment during phase 2, with fixed appliances, resulted in significant maxillary forward growth restriction and facial convexity reduction. Conclusion: Major Class II skeletal and dentoalveolar anteroposterior correction was obtained during phase 1, with the Bionator. Phase 2, with fixed appliances only produced a significant maxillary forward growth restriction and facial convexity reduction, without any significant dentoalveolar change.

Keywords: Malocclusion, Angle Class II. Activator appliances. Orthodontics, corrective. 


\section{Introduction}

The general effects of the Bionator are similar to those of other functional appliances and include dental and skeletal effects. Some authors ${ }^{1-3}$ stated that there is little evidence to support the claim that functional appliances significantly affect mandibular growth. However, other studies have suggested that mandibular length can be increased with functional appliance treatment ${ }^{4-11}$ and that functional therapy enhances differential growth between maxilla and mandible $e^{3,10,12-14}$.

A number of authors are in agreement that the most significant treatment effects are restricted to dentoalveolar changes..$^{2,3,15}$ Dolce et al. ${ }^{16,17}$ and Tulloch et al. ${ }^{18}$ stated that any skeletal effects from phase 1 treatment disappear by the end of fixed appliance treatment.

In spite of these controversial arguments, functional appliances are still used in early treatment of Class II division 1 malocclusion because they can produce excellent results $35,9,14,19,20$. In addition, functional appliances offer an effective first phase of orthopedic and orthodontic correction before a second phase of additional orthodontic correction and finishing 21,22 .

As evidenced in the literature $1,3,13,23$, the first phase with functional appliances results in some unwanted dentoalveolar side effects such as palatal tipping of the maxillary incisors, buccal tipping of the mandibular incisors and extrusion of the posterior dental segment. Thus, it is argued whether the second phase of fixed appliances orthodontic correction can improve these unfavorable dentoalveolar side effects. The effects of fixed appliances on two-phase orthopedic-orthodontic treatment has not been specifically investigated $8,16-18,22,24$. Therefore, the purpose of this work was to investigate the contribution of phase 2 with fixed appliances, after Bionator treatment of Class II division 1 malocclusion, as compared to a matching control group.

\section{MATERIAL AND METHODS}

\section{Material}

This retrospective study comprised samples obtained from the files of the Orthodontic Department at Bauru Dental School, University of São Paulo that consisted of 120 lateral cephalometric head films of 40 patients. The sample was divided into control $(n=20)$ and experimental $(n=20)$ groups. The lateral cephalograms of the experimental group were obtained at the pretreatment stage, after the Bionator therapy and after the fixed appliance phase. For the control group they were obtained at a compatible time period.

\section{Experimental group (Group 1)}

This group consisted of 20 Class II, division 1 malocclusion patients (11 male; 9 female), with an initial mean age of 11.11 years $(S D=1.25$ years, range 9.27 to 14.0 years). Nine patients had a complete Class II, 7 had $3 / 4$ of Class II and 4 had half Class II anteroposterior molar relationship ${ }^{19}$. These patients underwent orthopedic treatment with the Bionator for a mean period of 1.49 years $(S D=0.41)$, followed by orthodontic treatment with fixed appliances for 1.83 years $(S D=1.04)$. There was a 
mean interval between the two phases of 0.83 years. The complete treatment time was 4.15years $(S D=1.46)$ and the patients concluded treatment at a mean age of 15.31 years $(S D=1.14$, range 12.99 to 17.49 years $)$.

When fixed appliance treatment was initiated, the corrected anteroposterior relationship was retained by using an extraoral headgear for 10 hours/day or Class II elastics on a nighttime-wear protocol. This active retention period lasted until the end of the second phase with fixed appliances.

\section{Control group (Group 2)}

From the longitudinal growth study sample of 20 subjects ( 11 male; 9 female) were selected. All subjects presented with a Class II, division 1 malocclusion and had never been orthodontically treated. The subjects in this group had an initial mean age of 11.12 years ( $S D=0.79$, range 10.16 to 13.9 years) and a final mean age of 15.34 years $(S D=2.20$, range 12.71 to 19.48 years). The mean observation period was 4.22 years $(\mathrm{SD}=1.91$, range 1.47 to 8.12 years).

\section{Methods}

The 120 lateral cephalograms were manually traced on acetate paper by a single investigator (L.S.N.) and then digitized (Numonics AccuGrid XNT, model A30TL.F, Numonics Corporation, Montgomeryville, Pa) (Figure 1; Table 1). These data were then stored in a computer and analyzed with Dentofacial Planner 7.02 (Dentofacial Planner Software Inc., Toronto, Ontario, Canada). This software also corrected the magnification factors of the experimental and control group radiographs. The magnifications of the experimental group radiographs were $6.0,9.8$ and $7.9 \%$, as they were taken on different $X$-ray machines, and the magnification in the control group radiographs was $6 \%$.

\section{Error study}

Within a three-week interval from the first measurement, twenty four randomly selected radiographs were retraced, redigitized, and re-measured by the same examiner. The casual error was calculated according to Dahlberg's formula ${ }^{25}\left(\mathrm{Se}^{2}=\Sigma \mathrm{d}^{2} / 2 n\right)$, where $d$ is the difference between duplicate measurements and $n$ is the number of double measurements. The systematic error was calculated with dependent $t$ tests, for $P<0.05$.

\section{Statistical analyses}

The age compatibility of the experimental and control groups at T1 (pre-treatment), T2 (after functional therapy) and T3 (after orthodontic treatment with fixed appliances) as well as their cephalometric characteristics were investigated with tests. The malocclusion severity compatibility was assessed with Chi-square tests at T1.

Treatment changes in phases 1 and 2 (T2-T1, T3-T2) were compared to changes in the control group with t tests. Results were considered significant for $P<0.05$.All statistical analyses were performed with Statistica software (Statistica for Windows - Release 6.0 - Copyright Statsoft, Inc. 2001). 


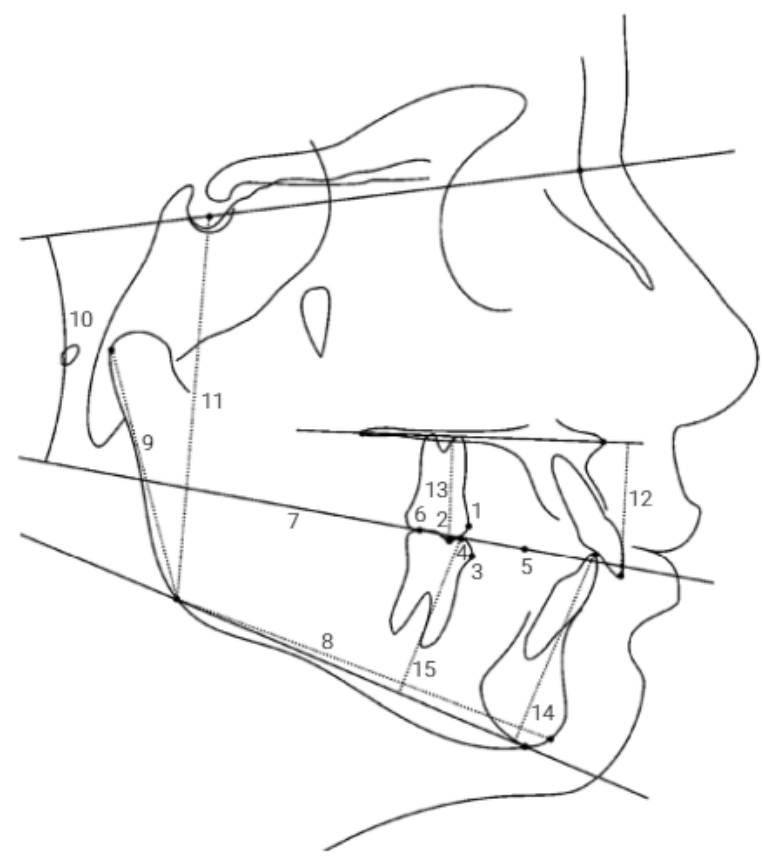

Figure 1. Unusual cephalometric landmarks, planes, and measurements. 1. MSUFM (mesial surface of the maxillary first molar): the most anterior point on the maxillary first permanent molar crown; 2 . MCUFM (mesial cusp of the maxillary first molar): the lowest point on the maxillary first permanent molar mesial cusp tip; 3. MSLFM (mesial surface of the mandibular first molar): the most anterior point on the mandibular first permanent molar crown; 4. MCLFM (mesial cusp of the mandibular first molar): the most superior point on the mandibular first permanent molar mesial cusp tip; 5. PMOC (premolar occlusal contact): first premolars or primary first molars intercuspation midpoint; 6. MOC (molar occlusal contact): first molars intercuspation midpoint; 7. Functional occlusal plane: a plane drawn through PMOC and MOC; 8. Go-Gn: distance between gonion and gnathion; 9. Co-Go: distance between condylion and gonion; 10. SN.FOP: angle formed between line SN and the functional occlusal plane; 11.S-Go: Distance between sella and gonion; 12. Mx1-PP: perpendicular distance between the incisal edge of the maxillary central incisor and palatal plane; 13. Mx6-PP: perpendicular distance between the mesiobuccal cusp of the maxillary first molar and the palatal plane; 14. Md1-MP: perpendicular distance between the incisal edge of the mandibular central incisor and mandibular plane; 15. Md6-MP: perpendicular distance between the mesiobuccal cusp of the mandibular first molar and mandibular plane.

\section{RESULTS}

The casual errors ranged from 0.21 (ANB) to 1.43 (Mx.PP). Paired t-tests demonstrated statistically significant systematic errors in only five variables ( $\mathrm{LAFH}, \mathrm{M} \times 6$-ANSperp, Md1-MP, Md6-MP and Wits).

No significant differences were observed between the groups regarding ages at T1, $\mathrm{T} 2$ and $\mathrm{T} 3$ and treatment time of each phase and the control group exhibited a smaller pretreatment malocclusion severity then the experimental (Tables 2 and 3). Cephalometrically, the experimental group had a significantly smaller mandibular body, greater skeletal Class II discrepancy, more labially tipped and protruded maxillary incisors, smaller dentoalveolar height of the maxillary incisors, greater overjet and greater Class II molar relationship (Table 4).

The intergroup comparisons show that the Bionator therapy (Phase 1) resulted in significant forward growth restriction in the maxillary complex, which contributed 
Table 1. Unusual cephalometric landmarks and measurements

\begin{tabular}{|c|c|}
\hline PgnPerp & $\begin{array}{l}\text { (pogonion perpendicular point): point arbitrarily located at the level of the upper incisors, } \\
\text { perpendicular to Go-Me plane, from pogonion (for digitizing purposes only) }\end{array}$ \\
\hline ANSPerp & $\begin{array}{l}\text { (anterior nasal spine perpendicular point): point arbitrarily located at the level of the lower } \\
\text { incisors, perpendicular to the palatal plane, from ANS. (for digitizing purposes only) }\end{array}$ \\
\hline Pt & $\begin{array}{l}\text { (pterygoid): point located in the intersection of the upper and posterior walls of the } \\
\text { pterygomaxillary fissure }\end{array}$ \\
\hline $\mathrm{CS}$ & (center of skull): point located in the intersection of lines Ba-N and Pt-Gn \\
\hline Mx6-ANSperp & $\begin{array}{l}\text { distance between the mesial surface of the upper first molar and anterior nasal spine } \\
\text { perpendicular. It determines the sagittal position of the upper first molar in relation to } \\
\text { the maxilla. Negative values were assigned to measurements behind the reference line. } \\
\text { Therefore a mesial molar movement was indicated by a decrease in the absolute values } \\
\text { of this variable }\end{array}$ \\
\hline Md6-Pgnperp & $\begin{array}{c}\text { distance between the mesial surface of the lower first molar and pogonion } \\
\text { perpendicular. It determines the sagittal position of the lower first molar in relation to } \\
\text { the mandible. Negative values were assigned to measurements behind the reference } \\
\text { line. Therefore a mesial molar movement was indicated by a decrease in the absolute } \\
\text { values of this variable }\end{array}$ \\
\hline Overjet & $\begin{array}{l}\text { distance from the incisal edge of the lower incisor to the incisal edge of the upper } \\
\text { incisor, as measured parallel to the functional occlusal plane }\end{array}$ \\
\hline Overbite & $\begin{array}{l}\text { distance from the incisal edge of the lower incisor to the incisal edge of the upper } \\
\text { incisor, as measured perpendicular to the functional occlusal plane }\end{array}$ \\
\hline Molar relationship & $\begin{array}{l}\text { horizontal distance of the perpendicular projections of the upper and lower first molars } \\
\text { mesial surfaces on the functional occlusal plane. Positive values were attributed when } \\
\text { the lower molars were mesial to the upper }\end{array}$ \\
\hline
\end{tabular}

Table 2. Intergroup compatibility evaluation regarding patients age and treatment time (t tests)

\begin{tabular}{|c|c|c|c|c|c|}
\hline \multirow{2}{*}{ Variables (years) } & \multicolumn{2}{|c|}{$\begin{array}{c}\text { Group } 1 \text { (experimental) } \\
\mathrm{n}=20\end{array}$} & \multicolumn{2}{|c|}{$\begin{array}{c}\text { Group } 2 \text { (control) } \\
\mathrm{n}=20\end{array}$} & \multirow{2}{*}{$\mathrm{p}$} \\
\hline & Mean & SD & Mean & SD & \\
\hline Initial age (T1) & 11.11 & 1.25 & 11.12 & 0.79 & 0.9725 \\
\hline Age After Bionator (T2) & 12.60 & 1.29 & 12.61 & 1.07 & 0.9663 \\
\hline Age After fixed appliance (T3) & 15.31 & 1.14 & 15.34 & 2.20 & 0.9629 \\
\hline Phase 1 duration - Bionator & 1.49 & 0.41 & 1.49 & 0.77 & 0,984 \\
\hline $\begin{array}{l}\text { Phase } 2 \text { duration - Fixed } \\
\text { appliances (with interval) }\end{array}$ & $2.66^{\star \star}$ & 1.04 & 2.72 & 1.90 & 0.072 \\
\hline Total treatment time & 4.15 & 1.46 & 4.21 & 1.91 & 0,979 \\
\hline
\end{tabular}

* Statiscally significant for $P<0.05$

** Fixed appliances treatment ( 1.83 years $)+$ Interval ( 0.83 years).

Table 3. Intergroup malocclusion severity compatibility evaluation (Chi-square test)

\begin{tabular}{lccc}
\hline 1st. Molars relationship at T1 & $\begin{array}{c}\text { Group 1 (experimental) } \\
\mathrm{n}=20\end{array}$ & $\begin{array}{c}\text { Group 2 (control) } \\
\mathrm{n}=20\end{array}$ & $\mathrm{p}$ \\
\hline $1 / 4$ of ClassII & 0 & 3 & \\
\hline Half Class II & 4 & 10 & $0,00245^{9}$ \\
\hline $3 / 4$ of Class II & 7 & 4 & \\
\hline Complete Class II & 9 & 3 & \\
\hline
\end{tabular}

Chi-square test: $\mathrm{df}=3$; Chi-square $=9,3896$ 
Table 4. Initial intergroup cephalometric compatibility evaluation (t tests)

\begin{tabular}{|c|c|c|c|c|c|}
\hline \multirow[t]{2}{*}{ Variables } & \multicolumn{2}{|c|}{$\begin{array}{l}\text { Group } 1 \text { (experimental) } \\
\qquad \mathrm{n}=20 \\
\end{array}$} & \multicolumn{2}{|c|}{$\begin{array}{c}\text { Group } 2 \text { (control) } \\
\mathrm{n}=20\end{array}$} & \multirow[t]{2}{*}{$\mathrm{p}$} \\
\hline & Mean & SD & Mean & SD & \\
\hline \multicolumn{6}{|l|}{ Maxillary component } \\
\hline $\operatorname{SNA}\left({ }^{\circ}\right)$ & 82.41 & 2.49 & 82.03 & 3.02 & 0.6709 \\
\hline Co-A (mm) & 82.92 & 3.68 & 85.01 & 3.97 & 0.0925 \\
\hline A-Nperp $(\mathrm{mm})$ & 0.00 & 3.41 & 0.09 & 2.71 & 0.9310 \\
\hline \multicolumn{6}{|c|}{ Mandibular component } \\
\hline $\operatorname{SNB}\left({ }^{\circ}\right)$ & 76.90 & 2.24 & 77.64 & 3.40 & 0.4215 \\
\hline P-Nperp (mm) & -6.97 & 5.74 & -5.49 & 4.19 & 0.3578 \\
\hline Co-Gn (mm) & 100.84 & 3.74 & 103.17 & 3.96 & 0.0626 \\
\hline Go-Gn (mm) & 66.42 & 3.33 & 68.74 & 3.60 & $0.0414^{*}$ \\
\hline Co-Go (mm) & 46.77 & 3.14 & 47.62 & 2.43 & 0.3422 \\
\hline Co.Go.Me $\left({ }^{\circ}\right)$ & 127.70 & 5.52 & 127.70 & 4.29 & 0.4610 \\
\hline \multicolumn{6}{|c|}{ Maxillomandibular relationship } \\
\hline ANB $\left({ }^{\circ}\right)$ & 5.52 & 1.81 & 4.36 & 1.77 & $0.0483^{*}$ \\
\hline Wits (mm) & 1.50 & 2.11 & -0.83 & 2.57 & 0.0034 * \\
\hline $\operatorname{NAP}\left({ }^{\circ}\right)$ & 9.16 & 4.52 & 7.48 & 4.64 & 0.2532 \\
\hline \multicolumn{6}{|l|}{ Growth pattern } \\
\hline SN.GoGn $\left(^{\circ}\right)$ & 32.18 & 5.03 & 30.55 & 4.25 & 0.2766 \\
\hline FMA $\left({ }^{\circ}\right)$ & 26.88 & 4.24 & 25.00 & 2.70 & 0.1024 \\
\hline SN.PP $\left({ }^{\circ}\right)$ & 7.56 & 2.97 & 7.43 & 3.02 & 0.8915 \\
\hline $\operatorname{SN} . F O P\left({ }^{\circ}\right)$ & 19.79 & 3.99 & 21.30 & 4.92 & 0.2934 \\
\hline LAFH $(\mathrm{mm})$ & 59.05 & 4.80 & 59.53 & 3.47 & 0.7218 \\
\hline S-Go $(\mathrm{mm})$ & 65.90 & 3.75 & 67.17 & 3.52 & 0.2745 \\
\hline \multicolumn{6}{|c|}{ Maxillary dentoalveolar component } \\
\hline Mx1.NA $\left({ }^{\circ}\right)$ & 30.61 & 6.86 & 22.60 & 5.91 & $0.0003^{*}$ \\
\hline Mx1-NA (mm) & 4.79 & 2.29 & 3.19 & 1.75 & $0.0176^{*}$ \\
\hline $\mathrm{Mx} 1-\mathrm{PP}(\mathrm{mm})$ & 24.44 & 2.32 & 26.52 & 2.26 & $0.0068^{*}$ \\
\hline Mx6-PP (mm) & 19.37 & 2.00 & 19.77 & 2.07 & 0.5383 \\
\hline Mx6-ANSperp (mm) & 33.51 & 2.24 & 33.03 & 2.30 & 0.5127 \\
\hline \multicolumn{6}{|c|}{ Mandibular dentoalveolar component } \\
\hline $\operatorname{Md1.NB}\left({ }^{\circ}\right)$ & 23.73 & 7.23 & 24.21 & 5.21 & 0.8108 \\
\hline Md1-NB (mm) & 3.39 & 2.46 & 3.75 & 1.79 & 0.6053 \\
\hline Md1-MP (mm) & 35.88 & 2.32 & 36.32 & 1.70 & 0.4987 \\
\hline Md6-Pgnperp (mm) & -30.54 & 1.56 & -30.77 & 2.31 & 0.7140 \\
\hline Md6-MP (mm) & 25.68 & 1.85 & 26.62 & 1.67 & 0.1018 \\
\hline \multicolumn{6}{|l|}{ Dental relationship } \\
\hline Overjet (mm) & 7.94 & 2.77 & 4.75 & 1.63 & $0.0001^{*}$ \\
\hline Overbite $(\mathrm{mm})$ & 4.09 & 1.96 & 4.95 & 1.55 & 0.1348 \\
\hline Molar Rel. (mm) & -0.87 & 1.21 & 0.12 & 1.14 & $0.0116 *$ \\
\hline
\end{tabular}

* Statiscally significant for $P<0.05$ 
to significant improvement of the maxillomandibular relationship and decrease in facial convexity. There was significant reduction of the maxillary incisor proclination and protrusion, vertical development of the maxillary incisors, vertical development restriction of the maxillary first molars, protrusion of the mandibular incisors, and vertical development of the mandibular molars. The overjet was significantly reduced and the molar relationship was significantly improved during the first phase of treatment (Table 5). Treatment during phase 2 , with fixed appliances, resulted in significant reduction of SNA and facial convexity (Table 6).

Table 5. Intergroup treatment changes evaluation during phase 1 (t tests)

\begin{tabular}{|c|c|c|c|c|c|}
\hline \multirow{2}{*}{ Variables } & \multicolumn{2}{|c|}{ Group 1 (experimental) $n=20$} & \multicolumn{2}{|c|}{ Group 2 (control) $n=20$} & \multirow{2}{*}{$\mathrm{p}$} \\
\hline & Mean & SD & Mean & SD & \\
\hline \multicolumn{6}{|l|}{ Maxillary component } \\
\hline SNA $\left({ }^{\circ}\right)$ & -0.38 & 1.04 & 0.32 & 0.83 & $0.0248 *$ \\
\hline Co-A (mm) & 0.77 & 1.89 & 2.44 & 2.09 & $0.0115^{\star}$ \\
\hline A-Nperp (mm) & -1.07 & 1.52 & 0.69 & 1.38 & $0.0005^{\star}$ \\
\hline \multicolumn{6}{|c|}{ Mandibular component } \\
\hline $\operatorname{SNB}\left({ }^{\circ}\right)$ & 1.14 & 1.15 & 0.51 & 1.10 & 0.0879 \\
\hline P-Nperp (mm) & 0.16 & 3.41 & 1.21 & 3.70 & 0.3547 \\
\hline Co-Gn (mm) & 3.33 & 2.74 & 3.98 & 2.46 & 0.4318 \\
\hline Go-Gn (mm) & 2.48 & 2.05 & 2.21 & 1.88 & 0.6667 \\
\hline Co-Go (mm) & 1.06 & 2.96 & 2.45 & 2.24 & 0.1011 \\
\hline Co.Go.Me $\left(^{\circ}\right)$ & 0.48 & 1.94 & -0.31 & 2.35 & 0.2535 \\
\hline \multicolumn{6}{|c|}{ Maxillomandibular relationship } \\
\hline ANB $\left(^{\circ}\right)$ & -1.53 & 1.05 & -0.15 & 1.17 & $0.0004^{\star}$ \\
\hline Wits (mm) & -1.58 & 2.26 & 0.52 & 2.13 & $0.0045^{\star}$ \\
\hline $\operatorname{NAP}\left({ }^{\circ}\right)$ & -3.11 & 2.16 & -0.34 & 2.26 & $0.0003^{\star}$ \\
\hline \multicolumn{6}{|l|}{ Growth pattern } \\
\hline SN.GoGn $\left({ }^{\circ}\right)$ & 0.27 & 1.46 & -0.12 & 1.62 & 0.4298 \\
\hline FMA $\left(^{\circ}\right)$ & 0.90 & 2.12 & -0.62 & 2.27 & 0.0349 \\
\hline SN.PP $\left(^{\circ}\right)$ & 0.45 & 1.34 & 0.53 & 1.14 & 0.8397 \\
\hline SN.FOP $\left({ }^{\circ}\right)$ & -0.95 & 3.96 & -2.00 & 2.33 & 0.3157 \\
\hline LAFH $(\mathrm{mm})$ & 1.94 & 2.35 & 1.99 & 2.15 & 0.9499 \\
\hline S-Go (mm) & 3.04 & 1.93 & 3.55 & 2.22 & 0.4429 \\
\hline \multicolumn{6}{|c|}{ Maxillary dentoalveolar component } \\
\hline Mx1.NA $\left({ }^{\circ}\right)$ & -5.70 & 4.96 & 0.61 & 3.27 & $0.0000 *$ \\
\hline Mx1-NA (mm) & -1.00 & 1.51 & 0.35 & 0.86 & $0.0013^{\star}$ \\
\hline $\mathrm{Mx1}-\mathrm{PP}(\mathrm{mm})$ & 1.29 & 0.92 & 0.33 & 0.80 & $0.0012 *$ \\
\hline Mx6-PP (mm) & 0.76 & 1.09 & 1.72 & 1.48 & $0.0245^{\star}$ \\
\hline Mx6-ANSperp (mm) & -0.31 & 1.82 & -0.62 & 2.28 & 0.6314 \\
\hline \multicolumn{6}{|c|}{ Mandibular dentoalveolar component } \\
\hline Md1.NB $\left(^{\circ}\right)$ & 5.29 & 7.81 & 1.61 & 3.17 & 0.0587 \\
\hline Md1-NB (mm) & 1.97 & 2.08 & 0.38 & 0.75 & $0.0027^{\star}$ \\
\hline Md1-MP (mm) & 0.72 & 1.01 & 1.18 & 1.34 & 0.2233 \\
\hline Md6-Pgnperp (mm) & 0.75 & 1.18 & 0.24 & 1.21 & 0.1798 \\
\hline Md6-MP (mm) & 1.49 & 0.94 & 0.69 & 1.20 & $0.0232^{\star}$ \\
\hline \multicolumn{6}{|l|}{ Dental relationship } \\
\hline Overjet (mm) & -4.49 & 2.83 & 0.11 & 1.83 & 0.0000 * \\
\hline Overbite (mm) & -1.48 & 2.44 & -0.77 & 1.85 & 0.3093 \\
\hline Molar Rel. (mm) & 3.01 & 1.80 & 0.33 & 1.26 & $0.0000^{*}$ \\
\hline
\end{tabular}

* Statiscally significant for $P<0.05$ 
Table 6. Intergroup treatment changes evaluation during phase 2 (t tests)

\begin{tabular}{|c|c|c|c|c|c|}
\hline \multirow{2}{*}{ Variables } & \multicolumn{2}{|c|}{ Group 1 (experimental) n=20 } & \multicolumn{2}{|c|}{ Group 2 (control) $n=20$} & \multirow{2}{*}{$\mathrm{p}$} \\
\hline & Mean & SD & Mean & SD & \\
\hline \multicolumn{6}{|l|}{ Maxillary component } \\
\hline SNA $\left({ }^{\circ}\right)$ & -0.81 & 1.31 & 1.14 & 2.83 & $0.0084^{*}$ \\
\hline Co-A (mm) & 2.99 & 2.73 & 2.57 & 3.52 & 0.6757 \\
\hline A-Nperp (mm) & 0.71 & 1.48 & 1.52 & 3.44 & 0.3396 \\
\hline \multicolumn{6}{|c|}{ Mandibular component } \\
\hline $\operatorname{SNB}\left({ }^{\circ}\right)$ & -0.09 & 1.61 & 1.04 & 2.53 & 0.1015 \\
\hline P-Nperp (mm) & 3.23 & 2.82 & 2.91 & 6.25 & 0.8333 \\
\hline Co-Gn (mm) & 5.85 & 4.16 & 4.96 & 4.93 & 0.5410 \\
\hline Go-Gn (mm) & 3.58 & 2.75 & 2.32 & 2.24 & 0.1216 \\
\hline Co-Go (mm) & 3.11 & 2.95 & 4.19 & 4.59 & 0.3811 \\
\hline Co.Go.Me $\left({ }^{\circ}\right)$ & -0.17 & 3.37 & -1.31 & 2.42 & 0.2287 \\
\hline \multicolumn{6}{|c|}{ Maxillomandibular relationship } \\
\hline $\operatorname{ANB}\left({ }^{\circ}\right)$ & -0.70 & 1.51 & 0.08 & 1.24 & 0.0837 \\
\hline Wits $(\mathrm{mm})$ & 1.22 & 2.15 & 1.33 & 2.66 & 0.8862 \\
\hline $\operatorname{NAP}\left({ }^{\circ}\right)$ & -2.70 & 4.10 & -0.24 & 2.66 & $0.0299 *$ \\
\hline \multicolumn{6}{|l|}{ Growth pattern } \\
\hline SN.GoGn $\left(^{\circ}\right)$ & -0.38 & 2.92 & -1.24 & 2.41 & 0.3192 \\
\hline FMA $\left(^{\circ}\right)$ & -1.97 & 2.28 & -1.57 & 2.59 & 0.6066 \\
\hline $\operatorname{SN} . P P\left({ }^{\circ}\right)$ & 0.44 & 1.79 & -0.23 & 2.48 & 0.3370 \\
\hline $\operatorname{SN} . F O P\left({ }^{\circ}\right)$ & -2.84 & 3.52 & -3.09 & 3.14 & 0.8139 \\
\hline LAFH (mm) & 3.02 & 3.47 & 2.01 & 3.86 & 0.3920 \\
\hline S-Go $(\mathrm{mm})$ & 4.06 & 3.53 & 3.18 & 4.77 & 0.5091 \\
\hline \multicolumn{6}{|c|}{ Maxillary dentoalveolar component } \\
\hline $\mathrm{Mx} 1 . \mathrm{NA}\left({ }^{\circ}\right)$ & 1.42 & 5.18 & -0.90 & 3.77 & 0.1149 \\
\hline Mx1-NA (mm) & 0.59 & 1.82 & -0.14 & 1.49 & 0.1766 \\
\hline $\mathrm{Mx1-PP}(\mathrm{mm})$ & 1.05 & 1.66 & 0.72 & 1.47 & 0.5166 \\
\hline Mx6-PP (mm) & 2.27 & 1.63 & 1.64 & 2.47 & 0.3432 \\
\hline Mx6-ANSperp (mm) & -1.36 & 3.06 & -1.26 & 1.76 & 0.9000 \\
\hline \multicolumn{6}{|c|}{ Mandibular dentoalveolar component } \\
\hline $\operatorname{Md} 1 . N B\left({ }^{\circ}\right)$ & 0.71 & 7.08 & -0.34 & 4.00 & 0.5688 \\
\hline Md1-NB (mm) & 0.19 & 1.97 & 0.16 & 1.45 & 0.9493 \\
\hline Md1-MP (mm) & 1.74 & 1.69 & 1.32 & 1.94 & 0.4694 \\
\hline Md6-Pgnperp (mm) & -0.47 & 1.29 & 0.47 & 1.66 & 0.0526 \\
\hline Md6-MP (mm) & 2.28 & 2.18 & 1.62 & 1.78 & 0.3013 \\
\hline \multicolumn{6}{|l|}{ Dental relationship } \\
\hline Overjet (mm) & -0.27 & 1.34 & -0.03 & 1.89 & 0.6388 \\
\hline Overbite (mm) & -0.27 & 1.60 & -0.09 & 1.71 & 0.7398 \\
\hline Molar Rel. (mm) & -0.02 & 1.34 & 0.04 & 1.51 & 0.8947 \\
\hline
\end{tabular}

* Statiscally significant for $P<0.05$ 


\section{DISCUSSION}

\section{Study design}

Experimental group - One of the criteria for selection of the experimental group was based on good results obtained at the end of the Bionator therapy. Patient compliance in nonextraction Class II treatment was a crucial factor for the case to be included in the sample, and this definitely reduced its size. Therefore, 20 patients were selected for this investigation. This number can be considered satisfactory to produce reliable results because similar studies with functional appliances also used samples of similar sizes or smaller ${ }^{1,23,26}$.

Only cooperative patients in both phases were included in the investigation. This fact is believed to exaggerate the magnitude of treatment response because it cannot be assumed that patients who defaulted would have responded to treatment in the same way as successfully treated cases ${ }^{26}$. Additionally, as with most retrospective studies, the patients who failed to complete treatment did not have a final cephalometric radiograph ${ }^{26}$.

Control group - 20 patients were selected for this group. The occlusal and cephaIometric Class II characteristics of the control group were milder than those of the experimental group at the pretreatment stage (Tables 3 and 4 ). However, other studies $3,26-28$ have also used control groups with milder Class II characteristics than the experimental group or even used a control group consisting in a combination of Class I and Class II malocclusions ${ }^{8}$.

The differences in the initial malocclusion severity between experimental and control groups are not likely to interfere in the results because the control group was used only to distinguish the two-phase treatment changes from those of normal growth. Some studies concluded that the growing changes during postpubertal development were similar in untreated Class I and Class II subjects, despite the differences in occlusal and cephalometric characteristics ${ }^{29,30}$. Palomo et al. ${ }^{30}$, in 2005, concluded that from 11 to 15 years of age the rate of shape and size changes of the craniofacial structures are very similar for both Class I and Class II subjects. Thus, the differences between the treated patients and the control group were attributed to the effects of treatment rather than to pre-existing differences. Besides, other characteristics as gender distribution, number of patients and observation period were matched.

\section{Phase 1 treatment changes}

Although the primary concerns of this investigation are the changes during phase 2 , a brief discussion of the changes during phase 1 is important to help in the understanding of the subsequent changes.

\section{Maxillary component}

There was significant restriction in maxillary forward displacement during Bionator therapy (Table 5). This result is in disagreement with previous studies that found no significant restriction of maxillary growth during Bionator therapy ${ }^{23,26}$. In contrast, oth- 
ers found some restrictive effect, particularly when SNA angle was investigated $3,4,7,31$. Mills ${ }^{9}$ pointed out that this restrictive effect could be related to lingual inclination of the maxillary incisors and the accompanying posterior remodeling of point A. Point A is a deep alveolar point rather than a true skeletal landmark. Thus, changes in teeth inclination would also change the location of this landmark and could not reflect true skeletal changes ${ }^{11}$.

\section{Mandibular component}

No significant intergroup differences were found in the mandibular components during phase 1 (Table 5). Thus, the changes displayed in Table 5 can be attributed to normal mandibular growth. The possibility of stimulating mandibular growth by means of the Bionator therapy was reported by some authors ${ }^{6-11}$ however, it was not confirmed in this research and in previous studies ${ }^{3}$.

\section{Maxilomandibular relationship}

The maxillomandibular relationship showed significant improvement and there was a significant reduction in facial convexity in the experimental group compared with the control, during phase 1 (Table 5). These changes seem to have resulted primarily from restriction in maxillary forward displacement, as previously discussed.

\section{Growth pattern}

As suggested in the literature $7,31,32$, this study demonstrated that functional appliances do not change the craniofacial growth pattern and no significant increase in the lower anterior face height was observed, contrary to previous findings ${ }^{33}$ (Table 5).

\section{Maxillary dentoalveolar component}

As previously reported, functional therapy produced palatal tipping and retrusion of the maxillary incisors ${ }^{3,13,23}$ and vertical development restriction of the maxillary first molars $3,31,34$ (Table 5). The palatal tipping and retrusion of the maxillary incisors is an expected treatment outcome of functional appliances due to their class II 'traction effect', resulting from contact of the labial bow with the incisors ${ }^{11}$. The palatal tipping of the maxillary incisors may have also contributed to the increase in vertical development of the maxillary incisors (Mx1-PP).

\section{Mandibular dentoalveolar component}

The mandibular incisors protruded significantly in the treated group during the orthopedic phase, corroborating previous studies 3,13,6,26 (Table 5). This effect is probably consequent to the resultant mesial force on the mandibular incisors induced by protrusion of the mandible $e^{6,26}$.

Mandibular first molar vertical development (Md6-MP) was greater in the experimental as compared to the control group, which is usually associated to the vertical and sagittal correction of Class II malocclusions ${ }^{3,26}$ (Table 5). Despite the greater increase in mandibular first molar vertical development (Md6-MP) in the experimental group, this did not result in significant changes in the LAFH. 


\section{Dental relationship}

Consequent to the skeletal and dentoalveolar changes discussed, molar relationship and overjet were significantly improved during Bionator treatment as compared to the control group (Table 5). These results are in agreement with a number of authors that states that the most significant treatment effects are restricted to dentoalveolar changes $3,15,35$.

\section{Phase 2 treatment changes}

The only significant changes during phase 2 were a significant reduction in SNA and in facial convexity. The maxillary restriction can be attributed to effects resulting from the application of extraoral forces and Class II elastics during the second phase of treatment. Consequently, there was a reduction in facial convexity (Table 6).

Even with a relatively long phase with fixed appliances (1.83 years), no significant dentoalveolar changes occurred in the experimental group as compared to the control (Table 6). However, the absence of significant dentoalveolar changes during phase 2 may be consequent to the fact that the lateral headfilms at T2 were obtained immediately after the Class II anteroposterior relationship correction with the Bionator. After the headfilms were obtained no active retention was used until phase 2 with fixed appliances was initiated. This period of time lasted a mean of 9.96 months. Therefore, some dentoalveolar anteroposterior correction may have relapsed during this period of time. Consequently, the use of extraoral forces and Class II elastics during phase 2 simply corrected the dentoalveolar anteroposterior discrepancy again, replacing the teeth at T3 to the same position they had occupied at T2, when the lateral headfilms were taken at the end of the functional appliance therapy. In this way, no dentoalveolar changes were shown between these two stages. The need to correct the dentoalveolar anteroposterior relationship again also explains the extended time of phase 2 .

\section{Clinical implications}

From these results one can conclude that the major dentoalveolar Class II anteroposterior correction is consequent to the Bionator during phase1. However one has to bear in mind that some anteroposterior relapse may have occurred in the interim between the end of phase 1 and beginning of phase 2 , when no active retention was used. This might have been responsible for prolonging the fixed appliance treatment period, associated with extraoral force and Class II elastics.

It was possible to conclude that:

1. During phase 1 (functional appliance treatment with the Bionator) there was significant redirection in maxillary forward growth, improvement in the maxillo-mandibular anteroposterior relationship, palatal tipping and retrusion of the maxillary incisors, protrusion of the mandibular incisor, overjet reduction and Class II molar relationship correction.

2. During phase 2 (fixed appliance treatment) there was only a significant maxillary forward growth restriction and facial convexity reduction, without any significant dentoalveolar change. 


\section{REFERENCES}

1. Nelson C, Harkness M, Herbison P. Mandibular changes during functional appliance treatment. Am J Orthod Dentofacial Orthop. 1993 Aug;104(2):153-61.

2. O'Brien K, Wright J, Conboy F, Sanjie Y, Mandall N, Chadwick S et al. Effectiveness of early orthodontic treatment with the Twin-block appliance: a multicenter, randomized, controlled trial. Part 1: Dental and skeletal effects. Am J Orthod Dentofacial Orthop. 2003 Sep;124(3):234-43; quiz 339.

3. Neves LS, Janson G, Cançado RH, de Lima KJRS, Fernandes TMF, Henriques JFC. Treatment effects of the Jasper Jumper and the Bionator associated with fixed appliances. Prog Orthod. 2014;15:54. doi: 10.1186/s40510-014-0054-9.

4. Oda H, Sandou M, Lin CM, Kamata M, Kawata T. Clarifying the mechanism of effect of the Bionator for treatment of maxillary protrusion: A percentile growth study. Eur J Paediatr Dent. 2016 Sep;17(3):213-219.

5. Santamaría-Villegas A, Manrique-Hernandez R, Alvarez-Varela E, Restrepo-Serna C. Effect of removable functional appliances on mandibular length in patients with class II with retrognathism: systematic review and meta-analysis. BMC Oral Health. 2017 Feb 1;17(1):52. doi: 10.1186/s12903-017-0339-8.

6. Op Heij DG, Callaert H, Opdebeeck HM. The effect of the amount of protrusion built into the bionator on condylar growth and displacement: a clinical study. Am J Orthod Dentofacial Orthop. 1989 May;95(5):401-9.

7. Jakobsson SO, Paulin G. The influence of activator treatment on skeletal growth in Angle Class II: 1 cases. A roentgenocephalometric study. Eur J Orthod. 1990 May;12(2):174-84.

8. DeVincenzo JP. Changes in mandibular length before, during, and after successful orthopedic correction of Class II malocclusions, using a functional appliance. Am J Orthod Dentofacial Orthop. 1991 Mar;99(3):241-57.

9. Mills JR. The effect of functional appliances on the skeletal pattern. Br J Orthod. 1991 Nov; 18(4):267-75.

10. Ghafari J, King GJ, Tulloch JF. Early treatment of Class II, division 1 malocclusion - comparison of alternative treatment modalities. Clin Orthod Res. 1998 Nov;1(2):107-17.

11. Illing HM, Morris DO, Lee RT. A prospective evaluation of Bass, Bionator and Twin Block appliances. Part I - The hard tissues. Eur J Orthod. 1998 Oct;20(5):501-16.

12. Keeling SD, Wheeler TT, King GJ, Garvan CW, Cohen DA, Cabassa S et al. Anteroposterior skeletal and dental changes after early Class II treatment with bionators and headgear. Am J Orthod Dentofacial Orthop. 1998 Jan;113(1):40-50.

13. Francisconi MF, Henriques JFC, Janson G, Freitas KMS, Santos PBD. Stability of Class II treatment with the Bionator followed by fixed appliances. J Appl Oral Sci. 2013 Nov-Dec;21(6):547-53. doi: 10.1590/1679-775720130002.

14. Madurantakam P. Fixed or removable function appliances for Class II malocclusions. Evid Based Dent. 2016 Jun;17(2):52-3. doi: 10.1038/sj.ebd.6401171.

15. Chadwick SM, Aird JC, Taylor PJ, Bearn DR. Functional regulator treatment of Class II division 1 malocclusions. Eur J Orthod. 2001 Oct;23(5):495-505.

16. Dolce C, Schader RE, McGorray SP, Wheeler TT. Centrographic analysis of 1-phase versus 2-phase treatment for Class II malocclusion. Am J Orthod Dentofacial Orthop. 2005 Aug;128(2):195-200.

17. Dolce C, McGorray SP, Brazeau L, King GJ, Wheeler TT. Timing of Class II treatment: skeletal changes comparing 1-phase and 2-phase treatment. Am J Orthod Dentofacial Orthop. 2007 Oct;132(4):481-9. 
18. Tulloch JF, Proffit WR, Phillips C. Outcomes in a 2-phase randomized clinical trial of early Class II treatment. Am J Orthod Dentofacial Orthop. 2004 Jun;125(6):657-67.

19. Wheeler TT, McGorray SP, Dolce C, Taylor MG, King GJ. Effectiveness of early treatment of Class II malocclusion. Am J Orthod Dentofacial Orthop. 2002 Jan;121(1):9-17.

20. Vargervik K, Harvold EP. Response to activator treatment in Class II malocclusions. Am J Orthod. 1985 Sep;88(3):242-51.

21. Nelson G. Phase I treatment. Am J Orthod Dentofacial Orthop. 1997 Feb;111(2):239-40.

22. Livieratos FA, Johnston LE, Jr. A comparison of one-stage and two-stage nonextraction alternatives in matched Class II samples. Am J Orthod Dentofacial Orthop. 1995 Aug;108(2):118-31.

23. Courtney M, Harkness M, Herbison P. Maxillary and cranial base changes during treatment with functional appliances. Am J Orthod Dentofacial Orthop. 1996 Jun;109(6):616-24.

24. Faltin KJ, Faltin RM, Baccetti T, Franchi L, Ghiozzi B, McNamara JA, Jr. Long-term effectiveness and treatment timing for Bionator therapy. Angle Orthod. 2003 Jun;73(3):221-30.

25. Dahlberg G. Statistical methods for medical and biological students. London: George Allen \& Unwin; 1940. p.122-32.

26. Almeida MR, Henriques JF, Almeida RR, Almeida-Pedrin RR, Ursi W. Treatment effects produced by the Bionator appliance. Comparison with an untreated Class II sample. Eur J Orthod. 2004 Feb;26(1):65-72.

27. Dermaut LR, van den Eynde F, de Pauw G. Skeletal and dento-alveolar changes as a result of headgear activator therapy related to different vertical growth patterns. Eur J Orthod. 1992 Apr;14(2):140-6.

28. Janson G, Caffer DC, Henriques JF, Freitas MR, Neves LS. Stability of Class II, division 1 treatment with the headgear-activator combination followed by the edgewise appliance. Angle Orthod. 2004 Oct; 74(5):594-604.

29. Pollard LE, Mamandras AH. Male postpubertal facial growth in Class II malocclusions. Am J Orthod Dentofacial Orthop. 1995 Jul; 108(1):62-8.

30. Palomo JM, Hunt DW, Jr., Hans MG, Broadbent BH, Jr. A longitudinal 3-dimensional size and shape comparison of untreated Class I and Class II subjects. Am J Orthod Dentofacial Orthop. 2005 May;127(5):584-91.

31. Righellis EG. Treatment effects of Frankel, activator and extraoral traction appliances. Angle Orthod. 1983 Apr;53(2):107-21.

32. McNamara JA Jr., Howe RP, Dischinger TG. A comparison of the Herbst and Frankel appliances in the treatment of Class II malocclusion. Am J Orthod Dentofacial Orthop. 1990 Aug;98(2):134-44.

33. Wieslander L, Lagerstrom $L$. The effect of activator treatment on Class II malocclusions. Am J Orthod. 1979 Jan;75(1):20-6.

34. McNamara JA Jr., Bookstein FL, Shaughnessy TG. Skeletal and dental changes following functional regulator therapy on Class II patients. Am J Orthod. 1985 Aug;88(2):91-110.

35. Tulley WJ. The scope and limitations of treatment with the activator. Am J Orthod. 1972 Jun;61(6):562-77. 